\title{
Article
}

\section{NPG-TRIS Thermal Storage System. Quantification of the Limiting Processes: Sublimation and Water's Adsorption}

\author{
Noelia De La Pinta ${ }^{1, *}$, Sergio Santos-Moreno ${ }^{1,2,3}{ }^{\circledR}$, Stephania Doppiu ${ }^{2}\left(\mathbb{D}\right.$, Josu M. Igartua ${ }^{1}(\mathbb{D}$, \\ Elena Palomo del Barrio ${ }^{2,4}$ and Gabriel A. López ${ }^{1}$ (D) \\ 1 Physics Department, University of the Basque Country UPV/EHU, 48940 Leioa, Spain; \\ ssantos@cicenergigune.com (S.S.-M.); josu.igartua@ehu.eus (J.M.I.); gabrielalejandro.lopez@ehu.eus (G.A.L.) \\ 2 Centre for Cooperative Research on Alternative Energies (CIC energiGUNE), Basque Research and \\ Technology Alliance (BRTA), Alava Technology Park, 01510 Vitoria-Gasteiz, Spain; \\ sdoppiu@cicenergigune.com (S.D.); epalomo@cicenergigune.com (E.P.d.B.) \\ 3 TECNALIA, Basque Research and Technology Alliance (BRTA), San Sebastián Technology Park, \\ 20009 Donostia-San Sebastián, Spain \\ 4 Ikerbasque, Basque Foundation for Science, 348013 Bilbao, Spain \\ * Correspondence: noelia.delapinta@ehu.eus
}

Citation: De La Pinta, N.; Santos-Moreno, S.; Doppiu, S.; Igartua, J.M.; Palomo del Barrio, E.; López, G.A. NPG-TRIS Thermal Storage System. Quantification of the Limiting Processes: Sublimation and Water's Adsorption. Crystals 2021, 11, 1200. https://doi.org/10.3390/ cryst11101200

Academic Editors: Aurora Nogales, Jan van Turnhout, Achilleas Pipertzis and Stavros X. Drakopoulos

Received: 6 July 2021

Accepted: 1 October 2021

Published: 5 October 2021

Publisher's Note: MDPI stays neutral with regard to jurisdictional claims in published maps and institutional affiliations.

Copyright: (c) 2021 by the authors. Licensee MDPI, Basel, Switzerland This article is an open access article distributed under the terms and conditions of the Creative Commons Attribution (CC BY) license (https:// creativecommons.org/licenses/by/ $4.0 /)$

\begin{abstract}
The NPG-TRIS binary system (NPG $=\left(\mathrm{CH}_{3}\right)_{2} \mathrm{C}\left(\mathrm{CH}_{2} \mathrm{OH}\right)_{2}=$ 2,2-dimetyl-1,3-propanodiol; TRIS $=\mathrm{NH}_{2} \mathrm{C}\left(\mathrm{CH}_{2} \mathrm{OH}\right)_{3}=$ 2-Amino-2-(hydroxymethyl)-1,3-propanediol) was intensively investigated as a thermal energy storage system, due to the reversibility of its phase transitions and their associated energy. An adapted methodology was applied to precisely quantify its sublimation tendency. Relevant thermochemical data were revisited and evaluated using some specific experimental procedures. We also determined that the widely accepted requirement of working in an inert atmosphere to avoid deviations due to hygroscopicity is not necessary. Nevertheless, to take advantage of the energetic properties of the NPG-TRIS system, closed containers will be required to avoid NPG losses, due to its quantitatively determined high sublimation tendency.
\end{abstract}

Keywords: thermal energy storage; phase change materials; thermophysical properties

\section{Introduction}

The high level of human activity is leading to the depletion of fossil and natural energy sources. As is well-known, society is continuously looking for alternative energy solutions to overcome this issue. Different approaches have been applied to find new alternative energy sources and new methods to store energy. In this context, the use of thermal energy storage (TES) is a suitable strategy to achieve efficiency in cold energy storage [1], in solar energy storage [2,3], in textile applications [4], in electronic devices [5,6], and in the building field [7,8], among others. In fact, during the 1970s global energy crisis some publications showed how phase change thermal energy storage was applied [9].

Since the 1970s, phase change materials (PCM) $[10,11]$ have been studied as potential thermal energy storage materials, due to the high values of the latent heat of phase transitions and their high energy density. Some of the most common systems are still being studied [12,13], and even carrying out ternary combinations between them [14]. Solid-solid and liquid-solid PCMs enable storing large amounts of thermal energy, with low associated costs, in small volumes [15-18], and nearly isothermal conditions [19]. However, liquid-gas PCMs are not attractive, because of their very large change of volume [20]. In addition, another critical parameter is the range of the temperatures in which the phase transition occurs, because this will be ultimately decisive in the choice of PCM for a potential application [21,22], Considering the mentioned criteria, Sharma et al. [23] analyzed thermal energy storage with PCMs for solar systems and spacecraft. Zhou et al. [24] reviewed thermal energy storage with PCMs in building applications, whereas Chen et al. [25] and Delgado et al. [26] focused their work on microencapsulated PCMs. 
Early studies about latent heat storage suggested the use of inorganic materials. Although these materials are good candidates at high temperatures, they present some disadvantages, such as a corrosive character, incompatibility with other materials, and segregation processes during the phase transition, among others [19,27]. Conversely, not having the mentioned drawbacks, for low temperatures the use of organic materials and their mixtures as PCMs has attracted more attention in recent years [15,19]. In this case, researchers have considered several properties as important factors: high thermal storage density; small volume change during the phase transition; repeatability of the phase change; thermal stability in the course of heating and cooling cycles; high density, with the ultimate goal of achieving small-sized storage containers; chemical stability; and no toxicity or flammability, among others.

In the wake of promising organic PCMs, during recent years, several studies have been made on systems of polyalcohols and amine derivatives of neopentane. These compounds are also called "plastic crystals", due to the plastic nature of the high-temperature phase. The orientational disorder in these plastic crystals gives rise to the reversible absorption or release of a large amount of heat upon their solid-solid phase transition to their plastic phases. In this sense, Murril et al. [28] showed that plastic crystals with large substituent groups have their solid-solid transition inhibited. Other studies about the mechanism of this transition were also reported $[2,29,30]$. The mechanism reported as responsible for the large energy exchange is the formation of hydrogen bonds, which break reversibly during the solid-state transformation [31,32]. In these works, the thermodynamic properties of the involved transitions (transition temperatures, energy changes, etc ... ) and recommendations for careful sample preparation procedures were emphasized.

The binary system NPG (2,2-dimetyl-1,3-propanodiol, $\left.\left(\mathrm{CH}_{3}\right)_{2} \mathrm{C}\left(\mathrm{CH}_{2} \mathrm{OH}\right)_{2}\right)$-TRIS (2-Amino-2-(hydroxymethyl)-1,3-propanediol, $\mathrm{NH}_{2} \mathrm{C}\left(\mathrm{CH}_{2} \mathrm{OH}\right)_{3}$ ) is one of the typical plastic crystals studied as a candidate for thermal energy storage. Although previous studies concerning neopentane derived compounds strongly recommended very controlled humidity conditions to avoid deviations from the desired composition, no quantitative data on the absorbed water content were reported, and only qualitative claims can be found [33-35]. With the aim of clarifying the reasons behind the claimed demanding conditions, the influence of environmental moisture in NPG, TRIS, and in a NPG-TRIS mixture were carefully investigated in a quantitative manner. In particular, samples with a peritectic composition were studied, due to their interest as a PCM (Figure S1) (see supplementary materials). To stabilize this influence two different samples were prepared, one under inert gas and the second under laboratory moisture. In addition, the effect of sublimation of NPG was studied under heating and cooling cycles in the NPG-TRIS binary system.

\section{Materials and Methods}

\subsection{Sample Preparations}

2,2-dimetyl-1,3-propanodiol (NPG, $\left(\mathrm{CH}_{3}\right)_{2} \mathrm{C}\left(\mathrm{CH}_{2} \mathrm{OH}\right)_{2}, \mathrm{CAS}$ number $\left.=126-30-7\right)$ and 2,2-dimethyl-1,3-diaminopropane (TRIS, $\mathrm{NH}_{2} \mathrm{C}\left(\mathrm{CH}_{2} \mathrm{OH}\right)_{3}, \mathrm{CAS}$ number = 77-86-1) were purchased from Aldrich with a purity of 99 and $99.8 \%$, respectively. Samples with a peritectic composition of NPG-TRIS system were prepared $\left(X_{\mathrm{NPG}}=0.515\right.$ and $X_{\text {TRIS }}=0.485$; in molar fraction) according to the reported binary equilibrium phase diagram [36] (Figure S1, Table S1). To prepare $5 \mathrm{~g}$ of the peritectic composition, $2.575 \mathrm{~g}$ of NPG and $2.425 \mathrm{~g}$ of TRIS were introduced in a ball-milling container with 3 stainless steel balls (1 g each). The milling was performed for $20 \mathrm{~min}$ to obtain a homogeneous sample.

Two different samples with peritectic composition were investigated. One of them was prepared in a glovebox with argon atmosphere and levels of oxygen and humidity below $0.1 \mathrm{ppm}\left(\mathbf{S}_{\mathrm{Ar}}\right)$. The other sample, $\mathbf{S}_{\mathbf{L a b}}$, was prepared and manipulated in ambient conditions (more or less with $70 \%$ of humidity). The $\mathbf{S}_{\mathrm{Ar}}$ was kept under inert conditions during the whole process, while the $\mathbf{S}_{\mathbf{L a b}}$ was stored at ambient conditions. 


\subsection{Equipments}

Differential scanning calorimetry (DSC) measurements were carried out using an MDSC Q-2000 calorimeter manufactured by TA Instruments (New Castle (DE), USA) with T-zero hermetically closed aluminum pans. For the calibration, sapphire and indium were employed. All the experiments were carried out in helium atmosphere. Depending on the experiment, different heating/cooling rates $\left(2 \mathrm{~K} \cdot \mathrm{min}^{-1}\right.$ and $\left.10 \mathrm{~K} \cdot \mathrm{min}^{-1}\right)$ and temperature ranges were scheduled. Thermogravimetric measurements were performed on a TA Discovery TGA (manufactured by TA Instrument in New Castle (DE), USA) using unclosed HT-aluminum pans under $\mathrm{N}_{2}$ atmosphere (flow rate of $10 \mathrm{~mL} \cdot \mathrm{min}^{-1}$ ) at $5 \mathrm{~K} \cdot \mathrm{min}^{-1}$ and $2.5 \mathrm{~K} \cdot \mathrm{min}^{-1}$ heating rates. Depending on the experiment, different temperature ranges were set. For temperature calibration of the TG equipment, pure nickel was used. Optical micrographs were produced on a MERLIN Carl Zeiss Instrument (manufactured by Zeiss Vision $\mathrm{GMbH}$ in Hallbergmoos, Germany), working temperature range from $308 \mathrm{~K}$ up to $433 \mathrm{~K}$. For sample preparation, a Mixer/Mill@High-Energy Ball Mill manufactured by SPEX sample Prep. In Metuchen, NJ, USA (2016 at 1060 cycles· $\mathrm{min}^{-1}$ was used as working conditions).

\subsection{Methods}

\subsubsection{Study of the Water Content}

The water content present in the samples prepared under laboratory conditions $\left(\mathbf{S}_{\mathbf{L a b}}\right)$ and in the NPG and TRIS compounds was determined by means of DSC. All measurements were acquired using a heating/cooling rate of $10 \mathrm{~K} \cdot \mathrm{min}^{-1}$. To prepare DSC specimens a 2-t weight was used to press the materials into $5 \mathrm{~mm}$ diameter pads. In order to quantify the water content in these samples, the value of the solidification (or fusion) enthalpy of distilled water $\left(\Delta H_{\text {solid }}\right)$ under the same conditions was verified in advance. The obtained value (Figure S2) of $\Delta \mathrm{H}_{\text {solid }}=6.02 \mathrm{~kJ} / \mathrm{mol}$ was in very good agreement with data reported in literature [37]. The range of temperature for the DSC measurements was selected in such a way that the melting point of water was always included; i.e., $\mathbf{S}_{\mathrm{Lab}}$ was measured from $243 \mathrm{~K}$ up to $433 \mathrm{~K}$, and NPG and TRIS were measured between 203 and $388 \mathrm{~K}$ and 203 and $413 \mathrm{~K}$, respectively, taking into account their corresponding melting points (396 K for NPG and $445 \mathrm{~K}$ for TRIS) and also the temperature of the peritectic reaction (Figure S1). Considering, the dependence of the heat flow, as a function of the temperature, the water content present in the samples was determined using the solidification enthalpy change of water. The associated error was not higher than $5 \%$. This error value is an upper conservative estimation, taking into account that the equipment was calibrated to a sapphire standard and the determination of enthalpy changes was verified for melting of an In reference at several heating/cooling rates, reaching a good agreement with literature data. Exactly the same methodology as applied for the determination of the enthalpy changes in the case of the In reference was used for the investigated samples.

\subsubsection{Sublimation Measurements}

Measurements of the evaporation rate ( $\mathrm{d} m / \mathrm{d} t$, rate of mass loss) of compounds were performed using TGA equipment. In order to obtain the temperature dependence of the vapor pressure of the sublimated compound $(p)$, an approximation of a Langmuir equation was used $[38,39]$. Since the Langmuir approach can only be applied when the compound sublimates to a vacuum, for our termogravimetric measurements a vaporization coefficient " $\alpha$ " had to be introduced. Therefore, the vapor pressure " $p$ " can be expressed as:

$$
p=-\left(\frac{\alpha}{A}\right)\left(\frac{d m}{d t}\right) \sqrt{\frac{2 \pi R T}{M}}
$$

where $\mathrm{d} m / \mathrm{d} t$ is the rate of mass loss, $A$ is the area of the evaporating surface, $M$ the molecular weight of the effusing substance, and $R$ is the gas constant. 
In our case, $\mathrm{d} m / \mathrm{d} t$ values were measured under isothermal conditions for $20 \mathrm{~min}$ every 5 and at $2.5 \mathrm{~K}$, maintaining the same area for each sample. A constant $(\alpha / A)$ value for all measurements was ensured by using powdered samples pressed $(2 t)$ into cylindrical pellets with identical dimensions (5-mm diameter) as those of the aluminum cylindrical crucibles used for the thermogravimetric measurements [40]. According to the mentioned approach, the dependence of the vapor pressure on the temperature was consistent with the ClausiusClapeyron equation, and the sublimation enthalpy $\Delta \mathrm{H}_{\text {sub }}$ can be determined using the following equation:

$$
\Delta H_{S u b}=R\left\lceil\ln \left(\frac{\left(\frac{d m}{d t}\right)_{T 1} \cdot \sqrt{T_{1}}}{\left(\frac{d m}{d t}\right)_{T 2} \cdot \sqrt{T_{2}}}\right)\right] \cdot\left(\frac{1}{T_{1}}-\frac{1}{T_{2}}\right)^{-1}
$$

where $T_{1}$ and $T_{2}$ are the temperatures corresponding to two consecutive isothermal measurements.

For calibration and testing of the method, benzoic acid was used as a well-established reference material (recommended by IUPAC for sublimation enthalpy measurements for compounds with a vapor pressure of approximately $0.1 \mathrm{~Pa}$ at room temperature (aprox. $298 \mathrm{~K})$ ). The TGA isothermal curves were measured every $5 \mathrm{~K}$ for 20 min from $318 \mathrm{~K}$ up to $370 \mathrm{~K}$ (Figure S3). Applying the previously described method, the experimental values obtained for the $\Delta \mathrm{H}_{\text {Sub }}$ of benzoic acid (Figure S4) were in agreement with data reported in the literature [41-43]. From the acquired data an error of about $5 \%$ in the determination of $\Delta \mathrm{H}_{\text {Sub }}$ was estimated as an upper conservative limit.

\section{Results}

\subsection{Study of the Water Content in the Samples}

In order to verify the reported special handling environmental conditions when manipulating NPG and TRIS and their mixtures [35,44-46], the water content present in the pure compounds and in a peritectic sample was reanalyzed and quantified using the method described in Section 2.3.1. As mentioned above, DSC measurements of the samples $\left(\mathbf{S}_{\mathrm{Lab}}\right.$, NPG and TRIS) were acquired in temperature ranges that include the temperature of water solidification (melting). Consistently, for all the samples, the enthalpy changes measured upon heating $\left(\Delta \mathrm{H}_{\text {Fusion }}\right)$ were very similar to those obtained upon cooling $\left(\Delta \mathrm{H}_{\text {Solid }}\right)$. To skip duplication, the analysis of the water content was only performed based on $\Delta \mathrm{H}_{\text {Fusion }}$ data obtained upon heating.

Figure 1 shows a DSC measurement acquired for $\mathbf{S}_{\mathrm{Lab}}$, from $240 \mathrm{~K}$ up to $433 \mathrm{~K}$. Carefully analyzing these curves, the value of heat flow around $273 \mathrm{~K}$ shows a tiny peak, which is directly related with the fusion process of water. The analysis of this peak shows an exothermic process linked the freezing process of water during cooling. Therefore, due to this, the water present in the samples is ascribed to the adsorption process of water.

To clarify this point, the adsorption capacity of water for NPG and TRIS was investigated. One sample of NPG sample was stored under laboratory moisture for 4 months, and other was kept in a glass bottle under dry conditions. In addition to the drying agent the bottle was connected to a rotary vacuum pump to assure rigorously dry conditions. In the case of the TRIS compound, an analogous procedure was applied. Subsequently, DSC measurements were acquired for a temperature range that contained the melting point of water for both NPG and TRIS samples (Figures 2 and 3, respectively). 


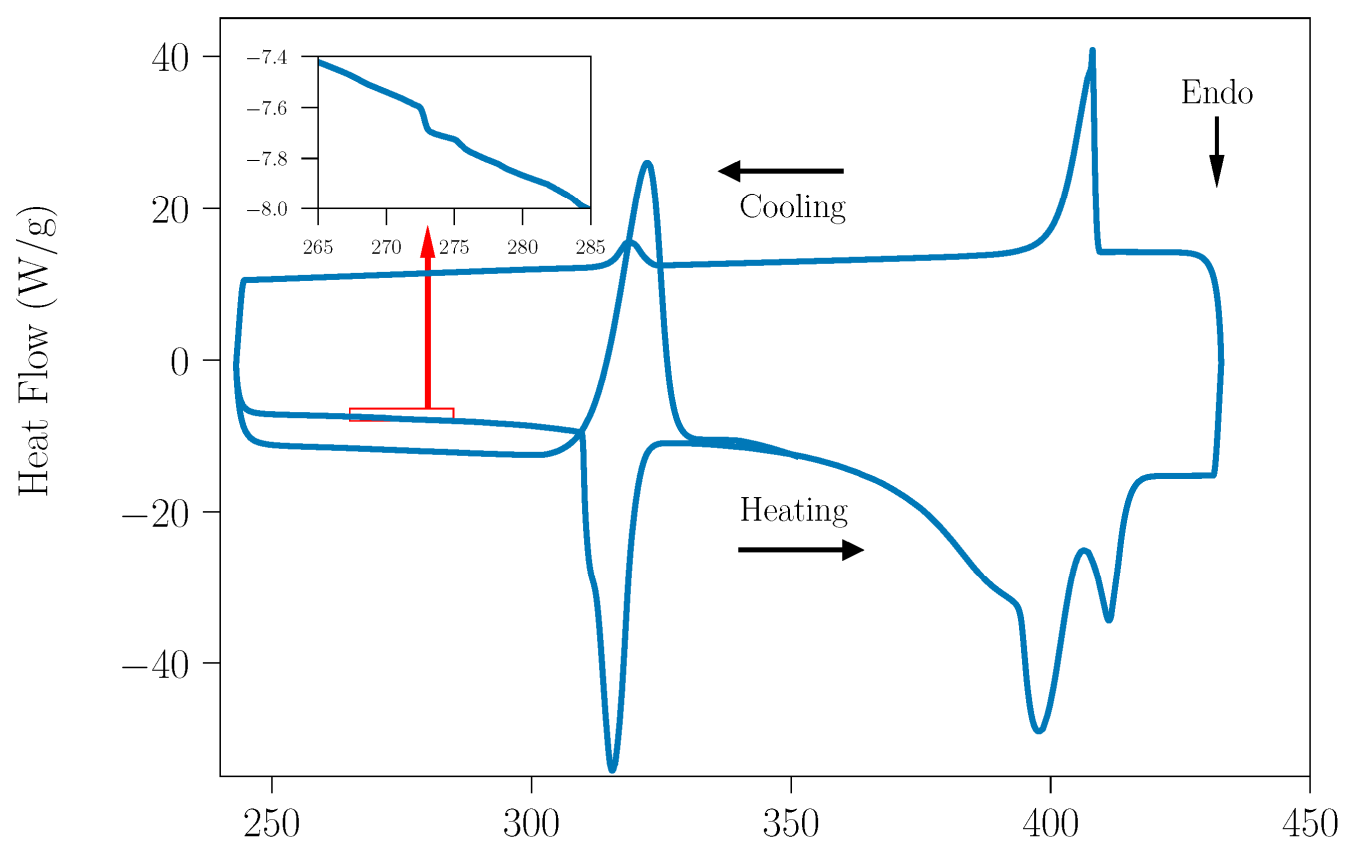

Temperature $(\mathrm{K})$

Figure 1. DSC of the $S_{\text {Lab }}$ (peritectic composition under laboratory humidity conditions) acquired at a $10 \mathrm{~K} \cdot \mathrm{min}^{-1}$ heating rate.

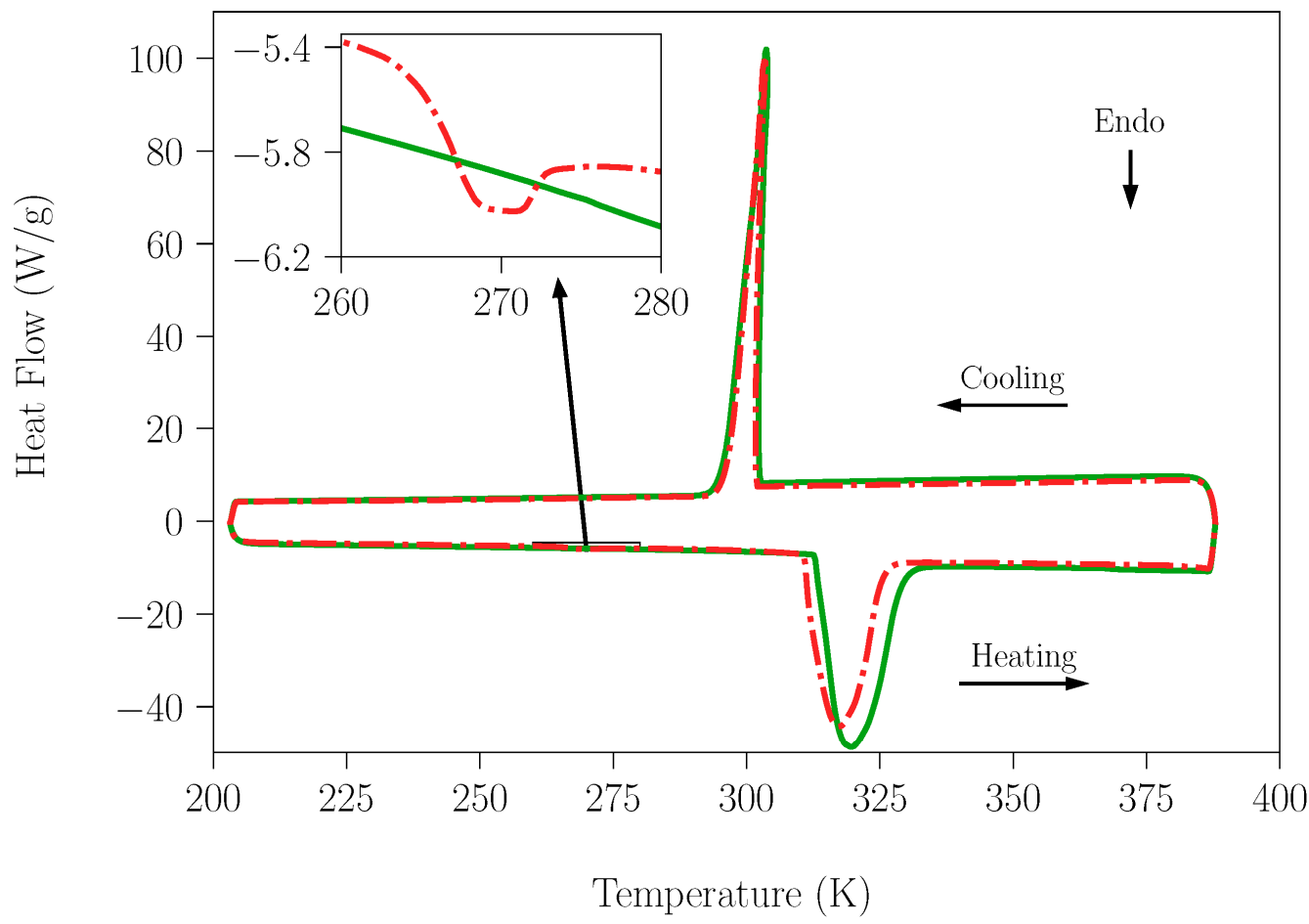

Figure 2. DSC measurement for the NPG samples; one stored under laboratory moisture for 4 months (red and dash solid line) and the second kept under dry conditions (green and solid line). The heating rate used was $10 \mathrm{~K} \cdot \mathrm{min}^{-1}$. 


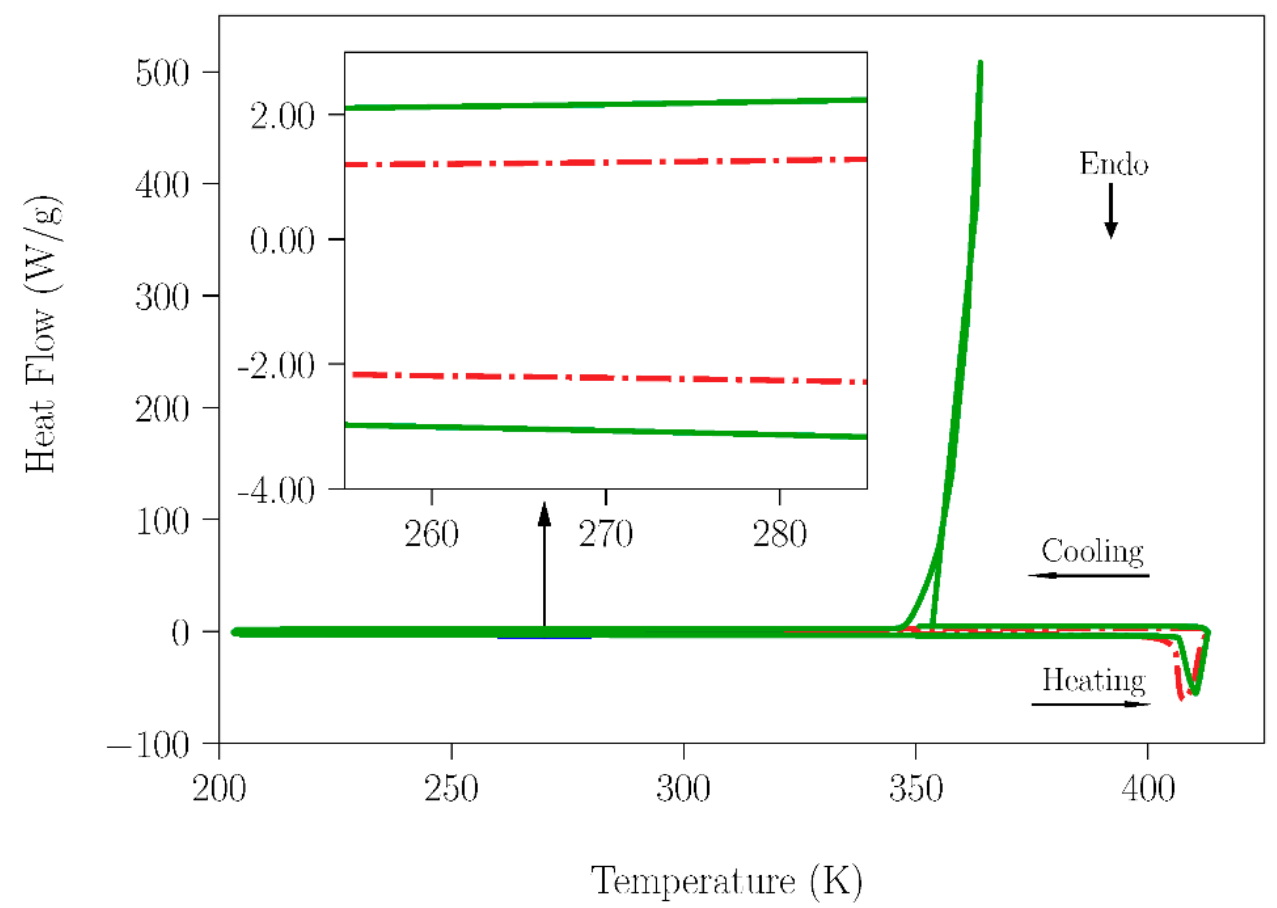

Figure 3. DSC measurement for the TRIS samples; one stored under laboratory moisture for 4 months (red and dash solid line) and the second under dry conditions (green and solid line). The heating rate used was $10 \mathrm{~K} \cdot \mathrm{min}^{-1}$.

As can be seen in Figure 2 (see the inset), a comparison of the results of heat flow for samples of NPG stored in laboratory conditions and under dry conditions shows a clear difference around the melting temperature of water. Indeed, although a tiny amount, some water is present in the NPG sample exposed to ambient humidity. However, in the case of the TRIS compound no peak around the melting temperature of water can be observed in the curves (see inset in Figure 3) of any of the samples. The values of enthalpy changes related to water fusion for the NPG and $\mathbf{S}_{\mathbf{L a b}}$ samples are gathered in Table 1. Using these data, the water content in the samples was estimated.

Table 1. Thermoanalytic data obtained by DSC for sample of water, $\mathbf{S}_{\mathbf{L a b}}$, and NPG compound.

\begin{tabular}{ccc}
\hline Compound & $\begin{array}{c}\text { Enthalpy Change Related } \\
\text { Adsorbed Water } \\
(\mathbf{J} / \mathbf{g})\end{array}$ & $\begin{array}{c}\text { Figures in the Article } \\
\text { Connected to Enthalpy } \\
\text { Changes }\end{array}$ \\
\hline Distilled $\mathrm{H}_{2} \mathrm{O}$ & 334.20 & Figure S2 \\
$\mathrm{NPG}$-adsorbed water & 1.07 & Figure 2 \\
$\mathrm{~S}_{\mathrm{Lab}}$-adsorbed water & $4.20 \times 10^{-3}$ & Figure 1 \\
\hline
\end{tabular}

The experimental values have an associated error of $5 \%$, as a conservative upper limit.

According to these data, it is clear that the TRIS compound did not take on any detectable water, even after storing the sample under laboratory conditions, and that the NPG compound could only absorb $0.32 \mathrm{wt}$.\% weight of water after exposing it to these humidity conditions for 4 months. Hence, considering this fact, it can be said that the adsorbed water in the $\mathbf{S}_{\mathrm{Lab}}$ sample derives exclusively from NPG. Using the peritectic composition and the data of the heat flow (Figure 1), the amount of water in the $\mathbf{S}_{\mathbf{L a b}}$ sample was determined to be just $0.003 \mathrm{wt}$.\% (of the NPG mass).

\subsection{Thermal Analysis of the Pure Components and of the Peritectic Compound}

Further analyzing the influence of the handling (humidity) conditions on the NPGTRIS system, the dependence of the molar heat capacity at constant pressure 
$\left(C_{\mathrm{p}}\left(\mathrm{J} \cdot \mathrm{mol}^{-1} \cdot \mathrm{K}^{-1}\right)\right)$ for NPG and TRIS compounds handled under laboratory conditions was compared with data acquired under inert atmospheres (Figures 4 and 5). $C_{p}$ data are also necessary to study the sublimation, which will be addressed in the next subsection. The data obtained in this work are in excellent agreement with adiabatic calorimetry measurements [31] and with modulated differential scanning calorimetry (MDSC) measurements [29].

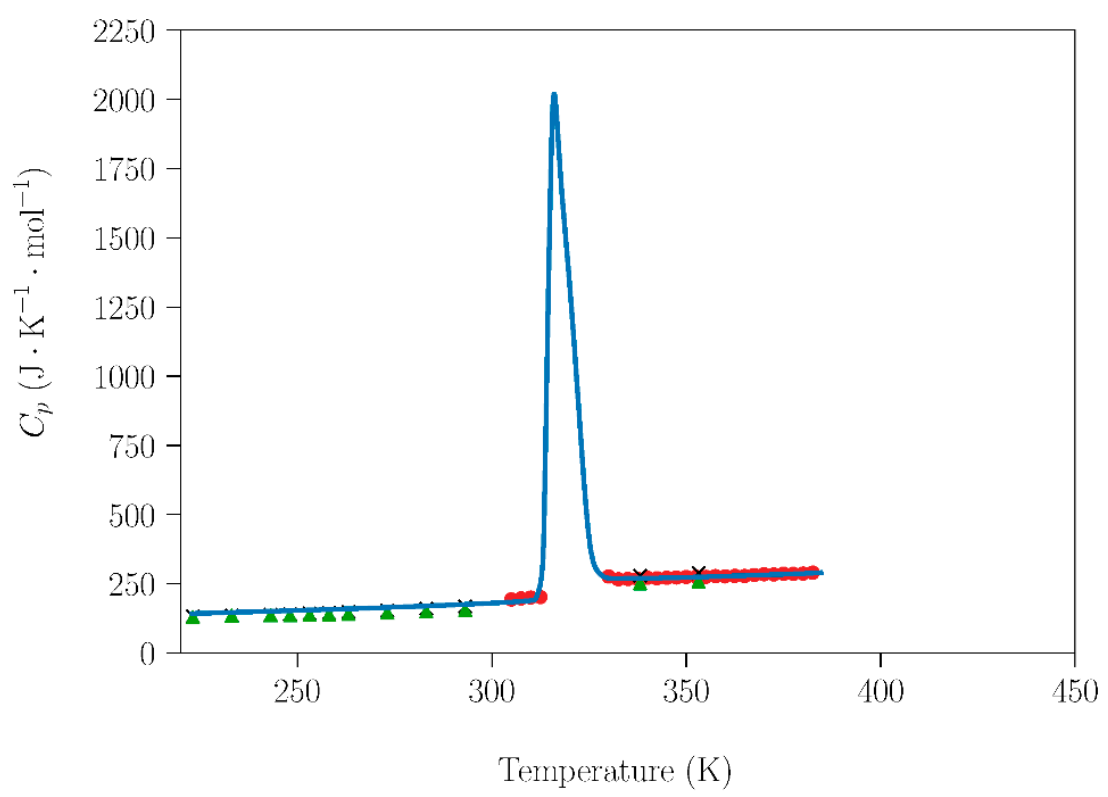

Figure 4. Dependence of molar heat capacity of NPG on temperature from $223 \mathrm{~K}$ up to $385 \mathrm{~K}$ (heating rate $2 \mathrm{~K} \cdot \mathrm{min}^{-1}$ ). Blue circles are the experimental results for NPG samples handled under noncontrolled environmental conditions. Red circles [31], green triangle, and black crosses [29] represent literature data for samples prepared under dry conditions in a glove box.

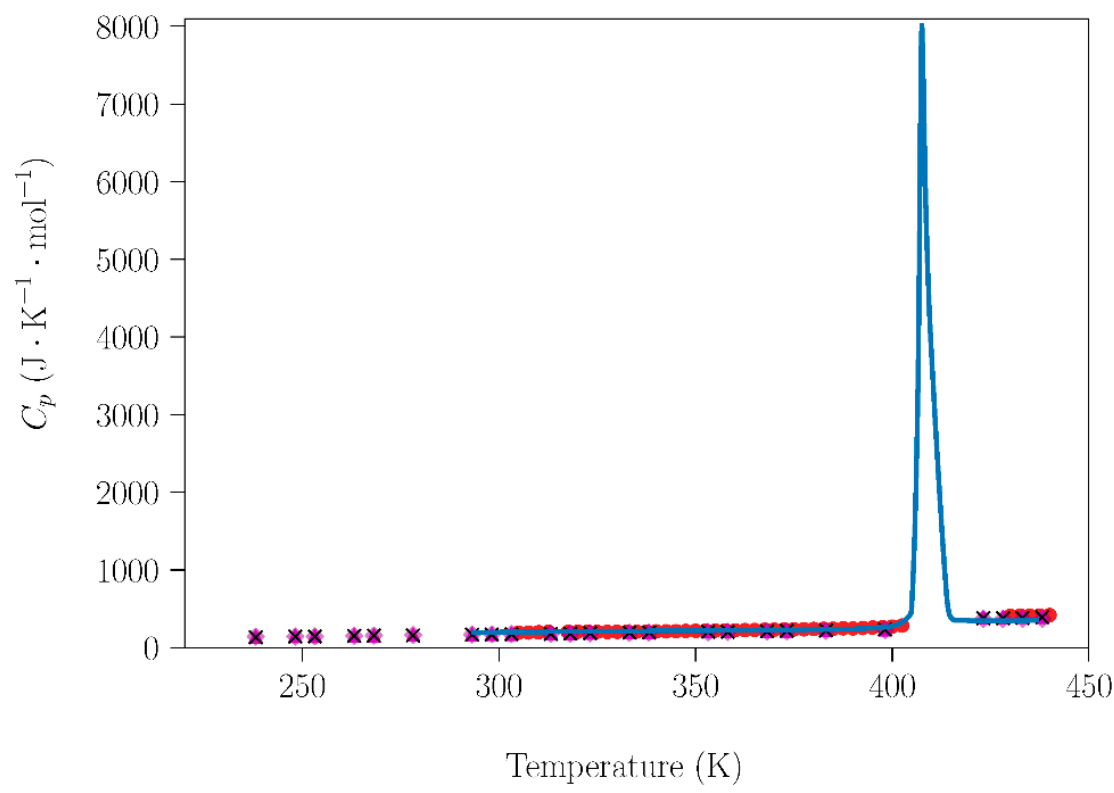

Figure 5. Dependence of molar heat capacity of TRIS on temperature from $223 \mathrm{~K}$ up to $433 \mathrm{~K}$ (heating rate $2 \mathrm{~K} \cdot \mathrm{min}^{-1}$ ). Blue circles are the experimental results for the TRIS handled under laboratory conditions. Red circles [31], green squares, purple rhombus, pink triangles, and black crosses [29] are literature data acquired using different methods for samples prepared under dry conditions in a glove box. 
Following the mentioned purpose, the phase transitions for NPG and TRIS were also revisited for samples handled under laboratory conditions. As is known, NPG appears as an ordered monoclinic phase below $313.8 \mathrm{~K}$. At this temperature, the compound transforms into the orientationally disordered phase (FCC). Meanwhile, this TRIS compound presents an orthorhombic (ordered) phase thermodynamically stable below $406.8 \mathrm{~K}$, where the ordered phase transforms into the disordered body-centered cubic (BCC) phase. The latter phase is stable up to $442.7 \mathrm{~K}$ (Figure S5). In the ordered phase of NPG, the molecules are connected by two different types of hydrogen bonds. The arrangement of these molecules forms zig-zag linear chains, which are established by Van der Waals interchain bonds [47]. The orthorhombic arrangement of TRIS shows a layered structure established by strong intermolecular hydrogen bonds, whereas the layers are connected by weak hydrogen bonds. This is due to the different electronegativity between the oxygen and nitrogen atoms present in the structure [48]. The value of the enthalpy change for the solid-solid phase transition $\left(\Delta H_{\mathrm{PT}}\right)$ was determined by the integrals from DSC measurement (Figure S6). As can be seen in Table 2, even though in our experiments the samples of NPG and TRIS were prepared and handled under laboratory conditions (without strict handling under dry conditions in a glove box), the experimental values of the enthalpy changes and temperatures of phase transitions are in very good agreement with the literature data.

Table 2. Thermal properties and phase transitions of commercial NPG and TRIS samples handled under laboratory conditions. Literature data are also included in this table.

\begin{tabular}{|c|c|c|c|c|c|c|c|}
\hline Compound & $\begin{array}{c}\text { Low } \\
\text { Temperature } \\
\text { Phase }\end{array}$ & $T_{\mathrm{PT}}(\mathrm{K})$ & $\begin{array}{c}\Delta H_{\mathrm{PT}} \\
(\mathrm{kJ} / \mathrm{mol})\end{array}$ & $\begin{array}{c}\text { High } \\
\text { Temperature } \\
\text { Phase }\end{array}$ & $T_{\mathrm{m}}(\mathrm{K})$ & $\begin{array}{c}\Delta H_{\mathrm{F}} \\
(\mathrm{kJ} / \mathrm{mol})\end{array}$ & Ref. \\
\hline \multirow{5}{*}{ NPG } & \multirow{5}{*}{ Monoclinic } & 315.0 & 13.6 & \multirow{5}{*}{ FCC } & 399.0 & 4.6 & [13] \\
\hline & & 315.0 & 12.1 & & 403.2 & 4.4 & [49] \\
\hline & & 314.6 & 12.8 & & 401.3 & 4.4 & [36] \\
\hline & & 313.8 & 13.0 & & 402.4 & 4.7 & [50] \\
\hline & & 315.2 & 13.0 & & 402.2 & 3.9 & our study \\
\hline \multirow{5}{*}{ TRIS } & \multirow{5}{*}{ Orthorhombic } & 408.0 & 32.7 & \multirow{5}{*}{ BCC } & 445.0 & 3.3 . & [13] \\
\hline & & 407.3 & 32.9 & & 446.0 & 3.0 & [51] \\
\hline & & 406.8 & 34.0 & & 442.7 & 3.7 & [52] \\
\hline & & 407.2 & 34.50 & & 445.4 & 3.4 & [50] \\
\hline & & 411.9 & 33.2 & & 443.9 & 3.3 & our study \\
\hline
\end{tabular}

$T_{\mathrm{PT}}=$ temperature of phase transition; $\Delta H_{\mathrm{PT}}=$ enthalpy of transition; $T_{\mathrm{m}}=$ melting temperature; $\Delta H_{\mathrm{F}}=$ latent heat of fusion; FCC $=$ face centered cubic; $\mathrm{BCC}=$ body centered cubic; low phase = phase at low temperature; high phase = phase at high temperature.

Having confirmed that the small amount of water that could be adsorbed in the pure compounds did not have influence on their transitions; the effect of the laboratory humidity on the peritectic reaction for sample $\mathbf{S}_{\mathbf{L a b}}$ was studied and was compared with the results obtained for the $\mathbf{S}_{\text {Ar }}$ sample. Analogous DSC curves acquired in the temperature range 293-433 K for both samples are shown in Figure 6. It is worth mentioning here that the different appearance of the curves lies in the different weights of the samples $\left(23.09 \mathrm{mg}-\mathrm{S}_{\mathrm{Lab}}\right.$ vs. $\left.8.9 \mathrm{mg}-\mathrm{S}_{\mathrm{Ar}}\right)$. It is evident that the small amount of water present in $\mathrm{S}_{\mathrm{Lab}}$ did not lead to a deviation from the peritectic composition and did not prevent or have a deleterious effect on this reaction with energetic interest. Table 3 summarizes the characteristic data for $\mathbf{S}_{\mathbf{L a b}}$ and $\mathbf{S}_{\mathrm{Ar}}$, which are in agreement with those reported in the literature $[13,20,28,32,44,53-55]$. To finish this section, peak number five in Figure 6 deserves particular comment. It appeared during the second heating process of the sample and is ascribed to the recrystallization process of the NPG compound. This process takes place starting at the temperature of the solid-solid transition of NPG up to $373 \mathrm{~K}$. Above this temperature, due to the beginning of the melting of NPG, the crystallinity of the sample is lost (see the progressive evolution in the optical micrographs shown in Figure S7). 


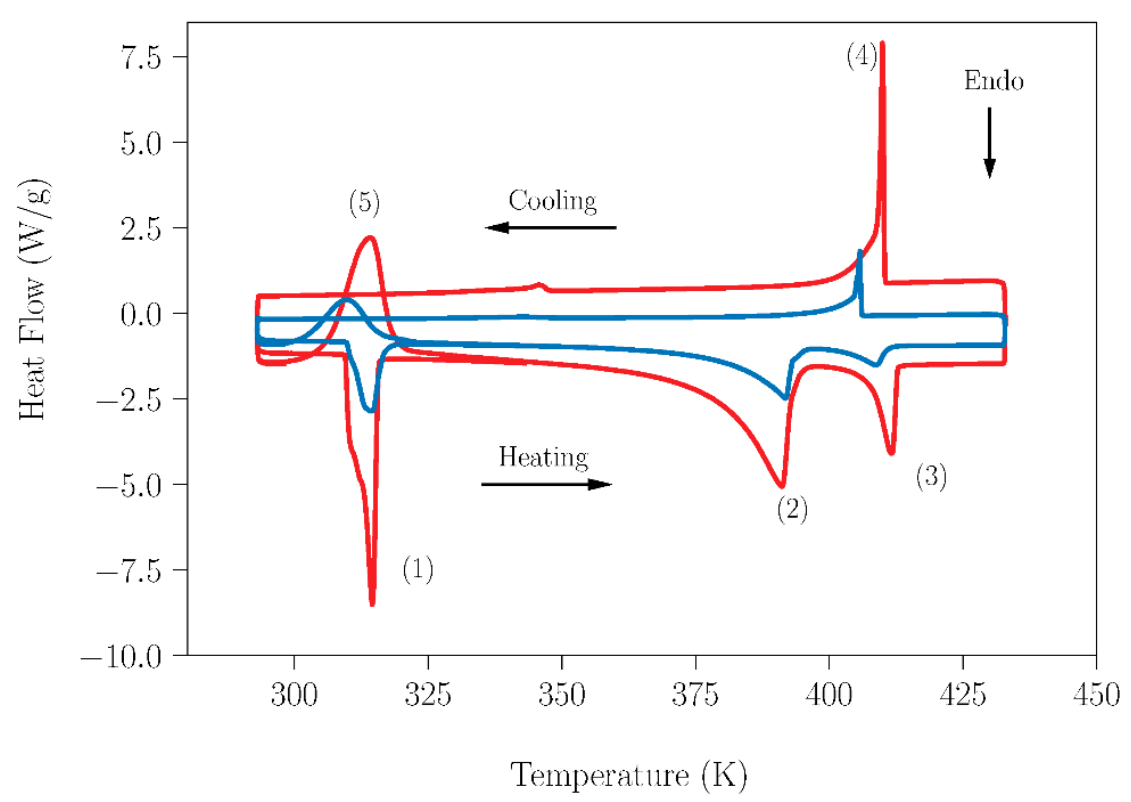

Figure 6. DSC measurements of $\mathrm{NPG}_{0.515} \mathrm{TRIS}_{0.485}$ peritectic samples in the temperature range 293-433 K. Blue lines correspond to the sample $\mathbf{S}_{\text {Ar }}$ (prepared and handled under dry conditions). Red lines correspond to the sample $\mathbf{S}_{\mathbf{L a b}}$ (prepared and handled under laboratory conditions). The heating/cooling rate used in this experiment was $1 \mathrm{~K} \cdot \mathrm{min}^{-1}$. Peak labels: (1) Eutectoid reaction 1; (2) Eutectoid reaction 2; (3) Peritectic melting; (4) Peritectic solidification and (5) Recrystallization process.

Table 3. Temperature and enthalpy values associated with each identified transition for the peritectic samples $\mathrm{NPG}_{0.515}$ TRIS $_{0.485} ; \mathbf{S}_{\text {Lab }}$ (without special handling, preparation, and storage) and $\mathbf{S}_{\text {Ar }}$ (with special handling, preparation, and storage).

\begin{tabular}{|c|c|c|c|c|c|}
\hline \multirow[b]{2}{*}{ Peak } & \multicolumn{2}{|c|}{$\mathrm{S}_{\mathrm{Lab}}$} & \multicolumn{2}{|c|}{$\mathrm{S}_{\mathrm{Ar}}$} & \multirow[b]{2}{*}{ Assignation } \\
\hline & Temperature(K) & $\Delta H(\mathrm{~J} / \mathrm{g})$ & Temperature(K) & $\Delta H(\mathrm{~J} / \mathrm{g})$ & \\
\hline 1 & 314.6 & 60.9 & 314.3 & 57.4 & $\begin{array}{l}\text { Eutectoid temperature } 1 ;[\mathrm{M}]+ \\
{\left[[\mathrm{O}] \rightarrow\left[\mathrm{C}_{\mathrm{F}}\right]+[\mathrm{O}]\right.}\end{array}$ \\
\hline 2 & 391.2 & 102.1 & 393.2 & 106.6 & $\begin{array}{l}\text { Eutectoid temperature } 2 ;\left[\mathrm{C}_{\mathrm{F}}\right]+ \\
{[\mathrm{O}] \rightarrow\left[\mathrm{C}_{\mathrm{F}}\right]+\left[\mathrm{C}_{\mathrm{I}}\right]}\end{array}$ \\
\hline 3 & 411.8 & 24.2 & 413.7 & 26.1 & $\begin{array}{c}\text { Peritectic invariant (melting) }\left[\mathrm{C}_{\mathrm{F}}\right] \\
+\left[\mathrm{C}_{\mathrm{I}}\right] \rightarrow[\mathrm{L}]+\left[\mathrm{C}_{\mathrm{I}}\right]\end{array}$ \\
\hline 4 & 410.0 & 30.4 & 407.5 & 28.9 & $\begin{array}{l}\text { Peritectic invariant (solidification); } \\
\qquad[\mathrm{L}]+\left[\mathrm{C}_{\mathrm{I}}\right] \rightarrow\left[\mathrm{C}_{\mathrm{F}}\right]+\left[\mathrm{C}_{\mathrm{I}}\right]\end{array}$ \\
\hline $5^{*}$ & 314.0 & 98.1 & 309.7 & 94.1 & $\begin{array}{l}\text { Recrystallization process, } \\
\text { solid-solid transformation }\end{array}$ \\
\hline
\end{tabular}

$\left(^{*}\right)$ 2nd cycle of thermal treatment. $[\mathrm{M}]=$ monoclinic; $[\mathrm{O}]=$ orthorhombic; $\left[\mathrm{C}_{\mathrm{F}}\right]$ = face-centered cubic; $\left[\mathrm{C}_{\mathrm{I}}\right]$ = body-centered cubic; $[\mathrm{L}]=$ liquid. The experimental values have associated error of $5 \%$, as a conservative upper limit.

\subsection{The Sublimation of NPG and Its Effect on $N P G_{0.515} T_{R I S} S_{0.485}$}

Using the method described in Section 2.3.2, the change of enthalpy during the sublimation process of a commercial NPG sample was studied in the temperature range where the crystal plastic phase of NPG exists; i.e., in the temperature range 313-363 K. The reasons for investigating this process are twofold. On the one hand, if sublimation takes place, compositional changes will occur, with the risk of losing the composition of interest (in this case, the peritectic composition). On the other hand, a certain amount of energy will be lost. The dependence of the evaporation rate $(\mathrm{d} m / \mathrm{d} t)$ of NPG on the temperature and the mass loss with time, measured under isothermal conditions for 20 min every $5 \mathrm{~K}$, were determined by TGA measurements (Figure S8). Plotting the data of the logarithm 
of the volatility rate of commercial NPG samples (Figure S9) and applying Equation (2), the dependence of the sublimation enthalpy change for NPG $\left(\Delta H_{\text {sub }}\right)$ was determined as a function of the temperature (Figure 7). It can be observed that $\Delta H_{\text {sub }}$ shows a decreasing tendency with increasing temperature. This downward evolution is not monotonic, due to the influence of the phase transitions of the NPG upon the sublimation process. The solid-solid phase transition was observed before $320 \mathrm{~K}$, and the effect of the melting process was determined at just over $358 \mathrm{~K}$.

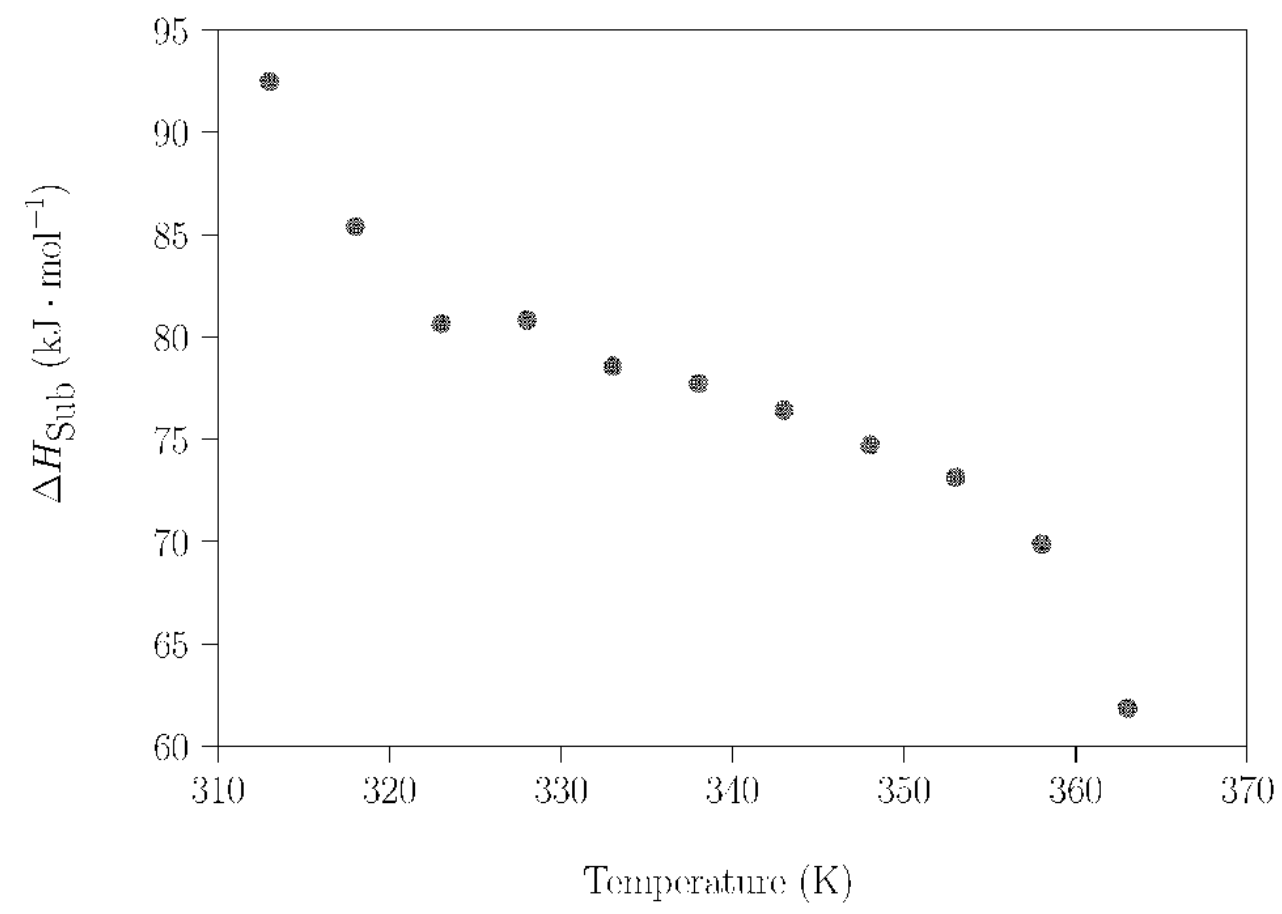

Figure 7. $\Delta H_{\text {sub }}$ of NPG as a function of the temperature in the range $313-363 \mathrm{~K}$.

Going one step further, the sublimation of NPG was investigated more precisely, applying the same procedure in a smaller temperature range (313-363 K) to avoid the influence of these phase transitions (experimental results shown in Figures S10 and S11 were used). In this case, the measurements were acquired under isothermal conditions for 20 min every $2.5 \mathrm{~K}$. For this selected temperature range, Figure 8 shows a remarkably linear dependence of $\Delta H_{\text {sub }}$ on the temperature; i.e., only the sublimation of NPG takes place.

The marked dependence of $\Delta H_{\text {sub }}$ on temperature was already noticed by Font et al. [56], although they did not report the temperature variation of the sublimation enthalpy for the whole plastic phase range. In this reference, the authors reported values of $\Delta H_{\text {sub }}$ acquired using a calorimetric method with Knudsen effusion cells, and only at two different temperatures close to the solid-solid phase transformation point: i) just before the solid-solid phase transition $\left(311.3 \mathrm{~K}, \Delta H_{\text {sub }}=87.6 \mathrm{~kJ} \cdot \mathrm{mol}^{-1}\right)$; and ii) just after the solid-solid phase transition $\left(318.6 \mathrm{~K}, \Delta H_{\text {sub }}=75.5 \mathrm{~kJ} \cdot \mathrm{mol}^{-1}\right)$. Taking into account the assumed associated error of $5 \%$, our experimental values of $\Delta H_{\text {sub }}$ for these two temperatures (Figure 7) are in an agreement with these data. 


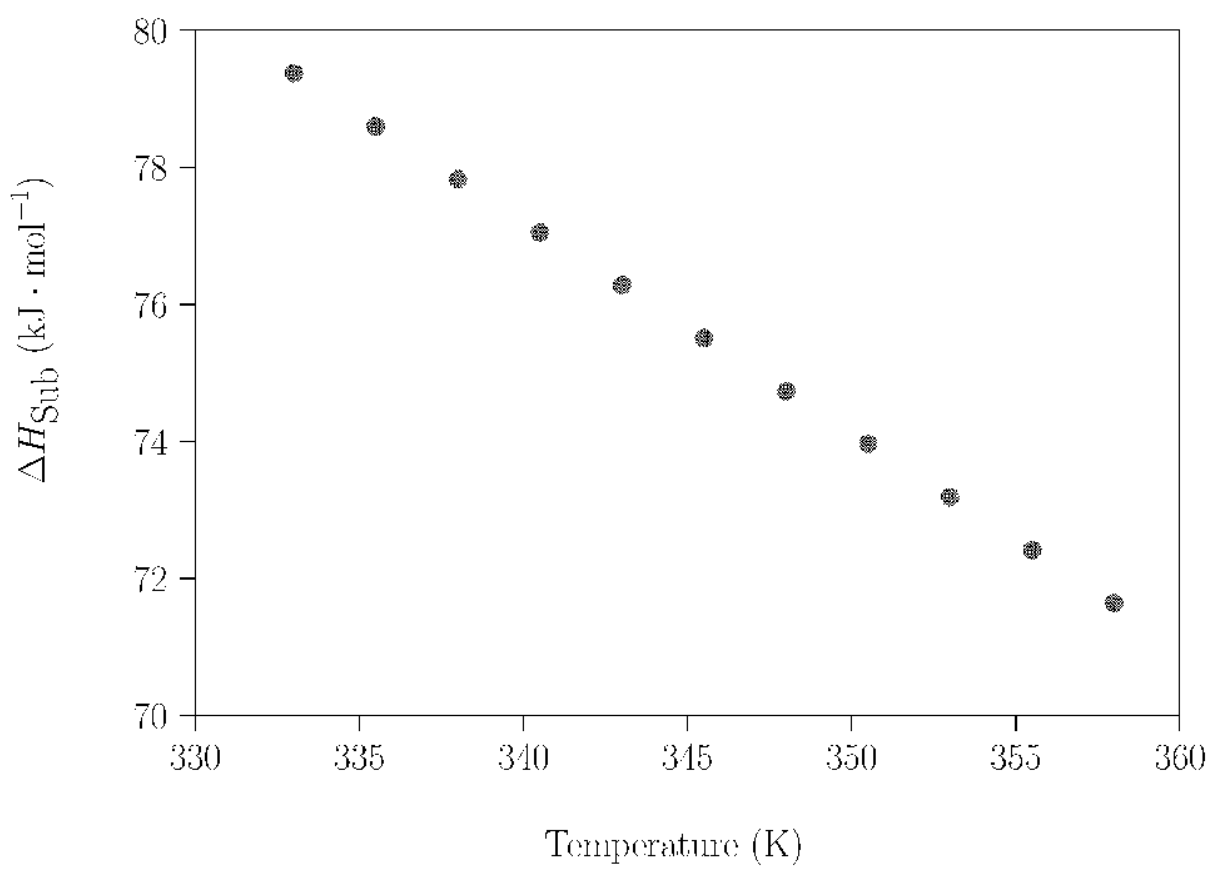

Figure 8. $\Delta H_{\text {sub }}$ of NPG as a function of temperature (between $333 \mathrm{~K}$ and $358 \mathrm{~K}$ ).

Having quantified the marked sublimation of NPG in a wide temperature range, it was required to investigate its effect on the behavior of the binary peritectic $\mathrm{NPG}_{0.515} \mathrm{TRIS}_{0.485}$ sample. Two $S_{\text {Lab }}$ samples with different treatments were analyzed by thermogravimetry. One of them $\left(\mathbf{S}_{\mathbf{L a b}}\right)$ was only ball milled, while the other $\left(\mathbf{S}_{\mathbf{L a b}+\mathrm{T}}\right)$ was ball-milled and then heated in a hermetically closed DSC holder from room temperature (RT) up to $448 \mathrm{~K}$; i.e., the fusion temperatures of NPG and TRIS were surpassed. Later, both samples $\left(\mathbf{S}_{\mathrm{Lab}}\right.$ and $\mathbf{S}_{\mathrm{Lab}+\mathrm{T}}$ ) were placed in an open thermobalance and the mass loss of these samples was measured (Figure 9), using the experimental procedure described in Section 2.3.2. Thermogravimetric measurements were made every $5 \mathrm{~K}$ upon heating from $310 \mathrm{~K}$ up to $400 \mathrm{~K}$.

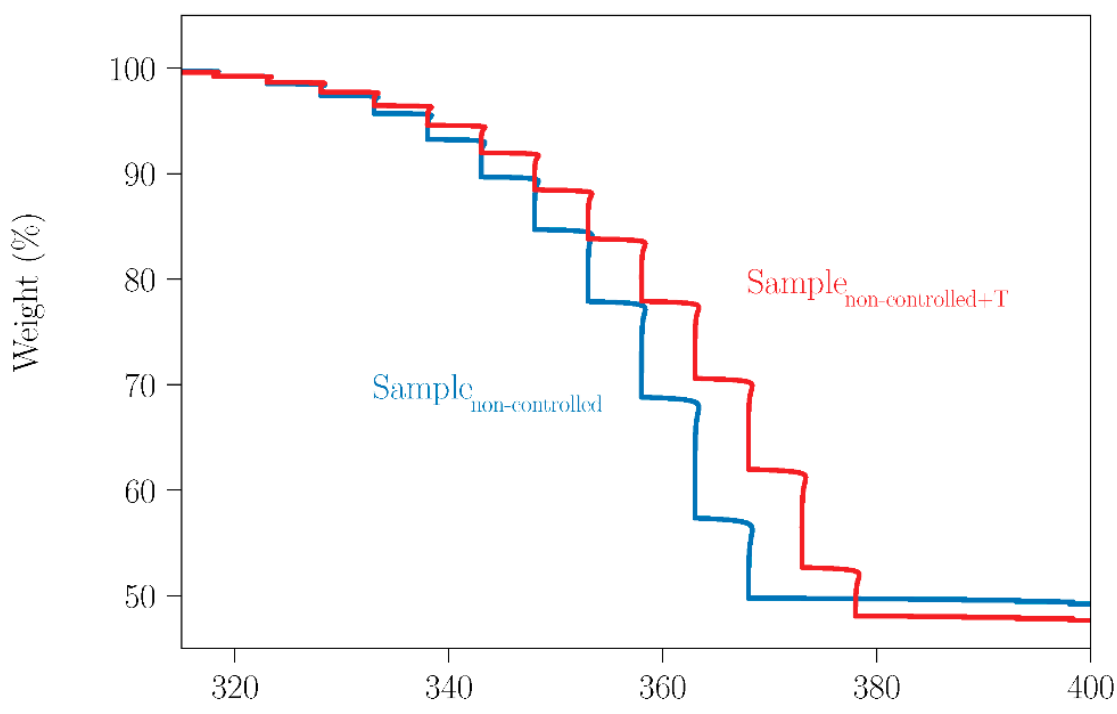

Temperature (K)

Figure 9. TGA measurement of $\mathbf{S}_{\mathbf{L a b}}$ and $\mathbf{S}_{\mathbf{L a b}+\mathbf{T}}$ samples, from $310 \mathrm{~K}$ up to $400 \mathrm{~K}$. 
Since TRIS has a low sublimation tendency in the investigated temperature range, the mass loss observed corresponds mainly to NPG sublimation. This can be deduced if the data gathered in Table 4 are taken into account. For both samples, the experimental values of the weight loss are almost the same as the nominal NPG contents of the peritectic samples, taking into account the experimental uncertainty. Therefore, sublimation of NPG in peritectic samples or other compositions will occur, in spite of previous treatments in a closed system. However, these treatments can clearly affect the sublimation process, as can be straightforwardly observed from the different trajectories of the curves.

Table 4. Thermoanalytic data for $S_{\mathrm{Lab}}$ and $\mathrm{S}_{\mathrm{Lab}+\mathrm{T}}$ samples.

\begin{tabular}{ccccccc}
\hline Sample & Step & $\boldsymbol{T}_{\mathbf{i}}(\mathbf{K})$ & $\boldsymbol{T}_{\mathbf{F}}(\mathbf{K})$ & $\mathbf{\%} \boldsymbol{\Delta} \boldsymbol{m}_{\text {experimental }}$ & $\mathbf{\%} \boldsymbol{\Delta} \boldsymbol{m}_{\text {theorical }}$ & Assignation \\
\hline $\mathrm{S}_{\mathrm{Lab}}$ & 1 & 308 & 368 & 50.3 & 51.5 & Sublimation of NPG \\
$\mathrm{S}_{\mathrm{Lab}+\mathrm{T}}$ & 1 & 308 & 378 & 52.0 & 51.5 & Sublimation of NPG \\
\hline
\end{tabular}

$T_{\mathrm{i}}=$ initial temperature; $T_{\mathrm{F}}=$ final temperature, $\% \Delta m_{\text {experimental }}=$ experimental mass loss percentage; $\% \Delta m_{\text {theorical }}$ $=$ theoretical mass loss percentage. The experimental values have an associated error of $5 \%$, as a conservative upper limit.

The experimental results of evaporation rate $(\mathrm{dm} / \mathrm{dt})$ as a function of time for $\mathbf{S}_{\mathrm{Lab}}$ and $\mathbf{S}_{\mathrm{Lab}+\mathrm{T}}$ are showed in Figure 10. For both samples, the experimental $\mathrm{d} m / \mathrm{d} t$ curves rise sharply with increasing time, followed by an abrupt drop to zero, which is caused by the total sublimation of NPG. Furthermore, it is clearly shown that the thermal treatment of the NPG-TRIS mixture affected the sublimation tendency. Therefore, applying appropriate thermal treatments can be a method of tuning the rate of mass loss caused by NPG sublimation.

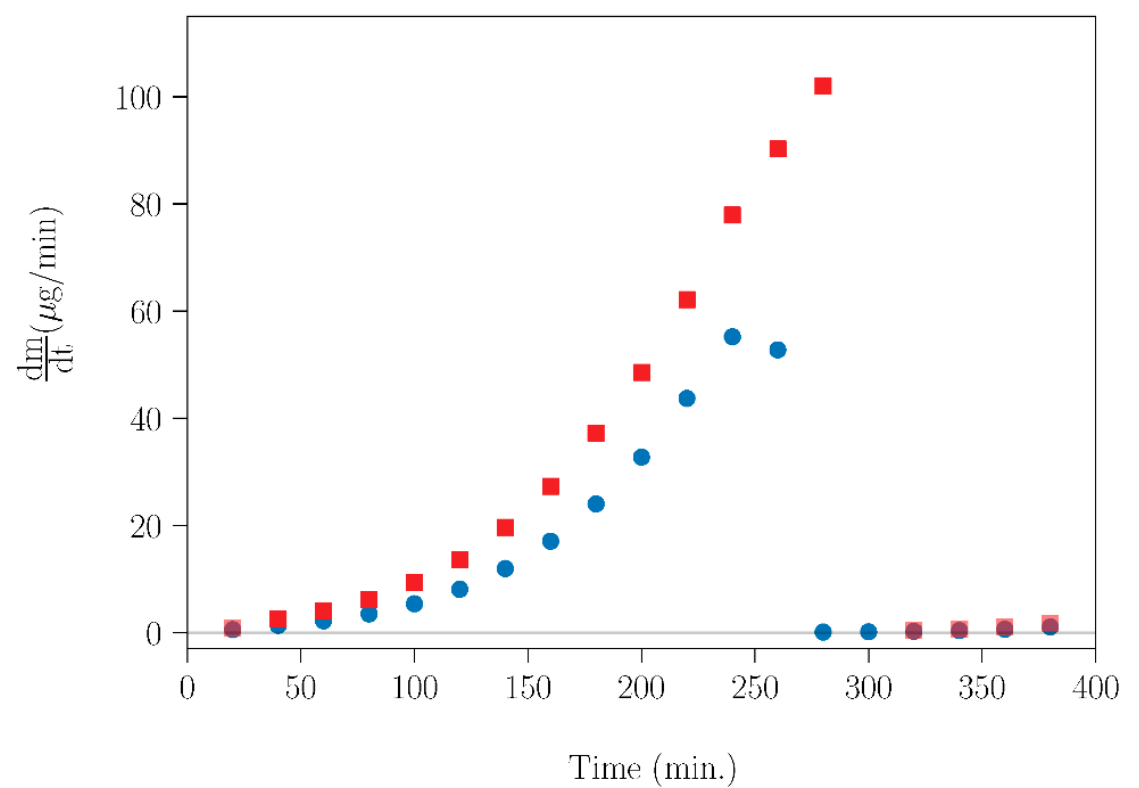

Figure 10. Evaporation rate $\left(\mathrm{dm} / \mathrm{dt}\right.$ ) for $\mathrm{S}_{\mathrm{Lab}}$ (blue circles) and $\mathbf{S}_{\mathrm{Lab}+\mathrm{T}}$ (red squares) over time. The measurements were carried out using an isothermal treatment for 20 min every $5 \mathrm{~K}$.

\section{Conclusions}

The experimental results in the current work clarify some practical aspects about the possibility of implementing NPG and its mixtures, for example peritectic NPG-TRIS, as thermal energy storage materials. In opposition to what is usually claimed in the literature, it was proven that environmental moisture does not significantly modify the peritectic composition (by water adsorption) to lead to a composition outside the reported peritectic reaction range $\left(0.46 \leq \mathrm{X}_{\mathrm{TRIS}} \leq 0.53 ; 0.54 \leq \mathrm{X}_{\mathrm{NPG}} \leq 0.47\right.$ at $\left.\mathrm{T}=410.7 \pm 2.0\right)$ [36]. In fact, the water content adsorbed by NPG exposed for 4 months under laboratory humidity 
conditions was a tiny amount $(0.32 \%$ of the NPG content), which did not affect the peritectic reaction. Consequently, we consider that it is possible to handle the NPG-TRIS binary under normal environmental conditions, without using the claimed strict dry conditions in a glove box.

The presence of water in the peritectic sample handled in non-controlled conditions $\left(\mathbf{S}_{\mathrm{Lab}}\right)$ and in NPG samples at the freezing temperature of pure water indicates clearly that this type of water entered the sample by physisorption, i.e., it is not crystallization water that could affect the phase transition of the compounds. Therefore, the adsorbed water only produces small compositional changes, which do not have significant effects during its handling.

In addition, it was shown that the sublimation of NPG happens during heating in open conditions for a NPG-TRIS mixture. Therefore, working a NPG-TRIS mixture with hermetically closed containers is a requirement that must be taken into account, to avoid changes in composition at invariant points. Hence, taking into account the relatively high sublimation tendency of NPG it is highly recommended to use closed systems for energy storage industrial applications where NPG will be employed.

Supplementary Materials: The following are available online at https: / www.mdpi.com/article / 10.3390/cryst11101200/s1, Figure S1. Phase diagram of the binary system NPG-TRIS. (x) DSC, (O) Guinier-Simon Technique, $(\Delta)$ solubility boundaries determine by s-ray powder diffraction at constant temperature, Table S1. Temperature and concentration values corresponding to the invariant points obtained by the phase diagram of the binary system NPG-TRIS, Figure S2. DSC of distiller water in MDSC Q-2000 calorimeter TA Instruments in the temperature range $203 \mathrm{~K}-313 \mathrm{~K}$ (heating rate was $\left.10 \mathrm{~K} \cdot \mathrm{min}^{-1}\right)$, Figure S3. Experimental dependence of evaporation rate $(\mathrm{d} m / \mathrm{d} t)$ on temperature at each temperature for Benzoic Acid, Figure S4. Dependence of the enthalpies of sublimation of the benzoic acid on temperature. Blue circles show our experimental data. Values of the literature data: red circles, green squares, and black triangles, Figure S5. Thermograph obtained at $2 \mathrm{~K} \cdot \mathrm{min}^{-1}$ heating rate for commercial samples (a) NPG and (b) TRIS, Figure S6. Dependence of the $\Delta H_{\mathrm{PT}}$ with the temperature for (a) NPG and (b) TRIS compounds, Figure S7. Photographs taken with the cooling of the sample at $333 \mathrm{~K}, 353 \mathrm{~K}$, and $373 \mathrm{~K}$ using a polarization microscope Zeiss Axioplan 2, Figure S8. Experimental results of TGA isothermal measurements for NPG commercial samples every $5 \mathrm{~K}$ for $20 \mathrm{~min}$ at temperature range 313-370 K. (a) Weight loss with the time. The different colors represent the isotherms every $5 \mathrm{~K}$ during $20 \mathrm{~min}$; (b) Dependence of evaporation rate $(\mathrm{d} m / \mathrm{d} t)$ on temperature, Figure S9. Dependence of the logarithm of evaporation rate of commercial NPG compound on reciprocal temperature. NPG sample was measured every $5 \mathrm{~K}$ from 313 up to $370 \mathrm{~K}$, where $\operatorname{Ln} p$ is $L n \frac{d m}{d t} \sqrt{T} ; t=$ time and $\mathrm{T}=$ Temperature, Figure S10. Dependence of evaporation rate of NPG on temperature from $333 \mathrm{~K}$ up to $358 \mathrm{~K}$. The measurement was carried out using isothermal conditions every $2.5 \mathrm{~K}$, Figure S11. Dependence of logarithm of evaporation rate of commercial NPG compound on reciprocal temperature. NPG sample was measured every $2.5 \mathrm{~K}$ from 333 up to $358 \mathrm{~K}$, where $\operatorname{Ln} p$ is $\operatorname{Ln} \frac{\mathrm{d} m}{\mathrm{~d} t} \sqrt{T} ; t=$ time and $T=$ Temperature.

Author Contributions: Conceptualization, N.D.L.P. and S.S.-M.; methodology, N.D.L.P., S.S.-M. and SD; data treatment and validation, N.D.L.P. and J.M.I.; investigation, S.S.-M. and S.D.; writingoriginal draft preparation, N.D.L.P.; writing—review and editing, S.S.-M., S.D., J.M.I., E.P.d.B. and G.A.L.; supervision, S.D. and G.A.L.; project administration, S.D., G.A.L. and E.P.d.B.; funding acquisition, G.A.L. and E.P.d.B. All authors have read and agreed to the published version of the manuscript.

Funding: This study was financially supported by the Basque Government (IT1301-19, IT1364-19) and through the Elkartek18 R\&D program, by the University of the Basque Country UPV/EHU (GIU19/019), and by the Ministry of Science and Innovation of Spain (PID2019-106644GB-I00).

Data Availability Statement: All data, models, or code that support the findings of this study are available from the corresponding author upon reasonable request.

Conflicts of Interest: The authors declare no conflict of interest. 


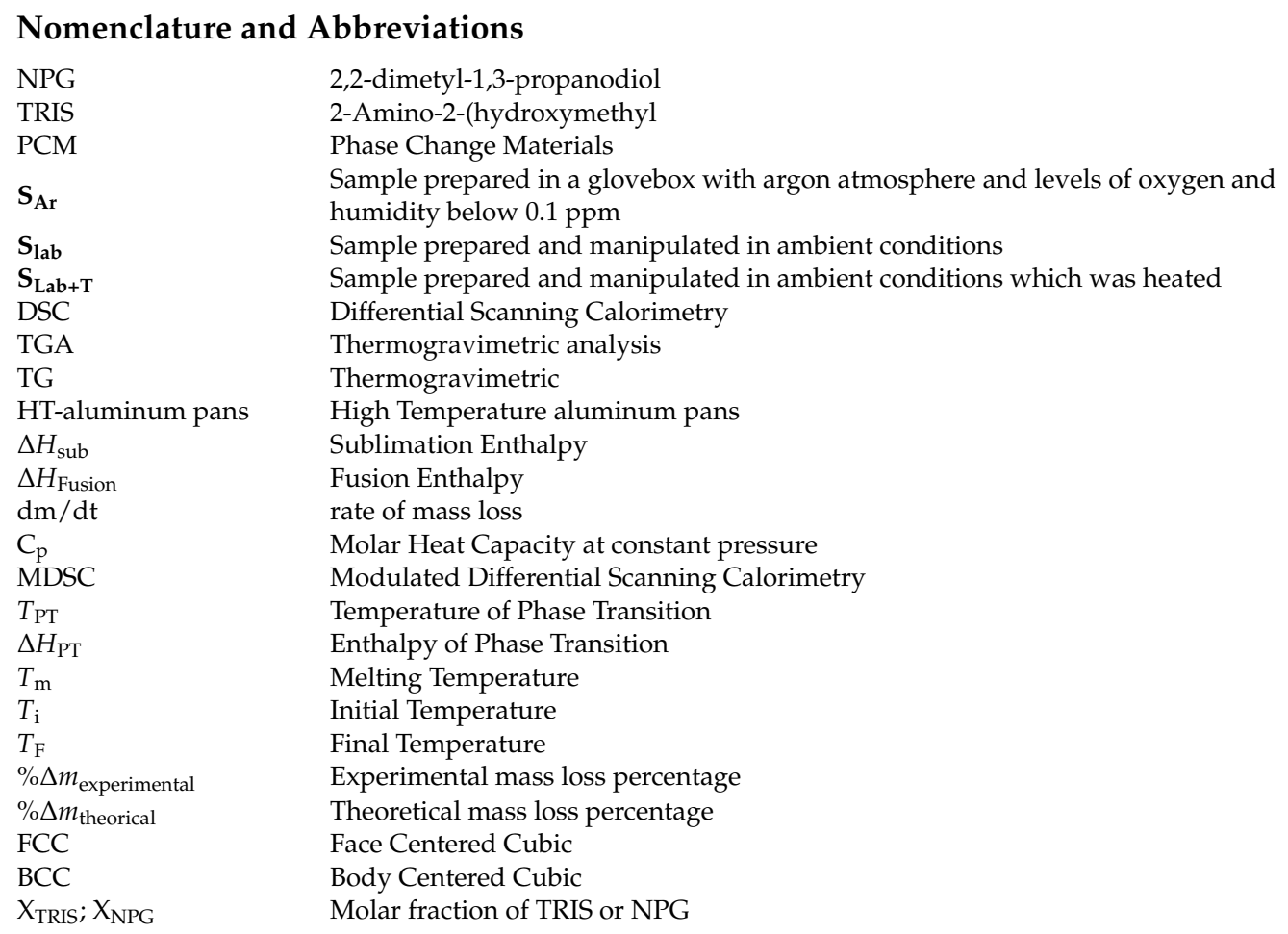

\section{References}

1. Saito, A. Recent advances in research on cold thermal energy storage. Int. J. Refrig. 2002, 25, 177-189. [CrossRef]

2. Gao, W.; Lin, W.; Liu, T.; Xia, C. An experimental study on the heat storage performances of polyalcohols npg, tam, pe, and ampd and their mixtures as solid-solid phase-change materials for solar energy applications. Int. J. Green Energy 2007, 4, 301-311. [CrossRef]

3. Chandra, D.; Fitzpatrick, J.J.; Jorgensen, G. Structure and Lattice Parameters of Pentaerythritol Above and Below Its PhaseTransition Temperature. Adv. X-Ray Anal. 1984, 28, 353-360. [CrossRef]

4. Sarier, N.; Onder, E. Organic phase change materials and their textile applications: An overview. Thermochim. Acta 2012, 540, 7-60. [CrossRef]

5. Hu, S.; Liu, B.; Li, Z.; Zhou, J.; Sun, Z. Identifying optimal dopants for $\mathrm{Sb}_{2} \mathrm{Te}_{3}$ phase-change material by high-throughput ab initio calculations with experiments. Comput. Mater. Sci. 2019, 165, 51-58. [CrossRef]

6. Pauken, M.; Emis, N.; Watkins, B. Thermal energy storage technology developments. AIP Conf. Proc. 2007, 880, 412-420. [CrossRef]

7. Cabeza, L.F.; Castell, A.; Barreneche, C.; De Gracia, A.; Fernández, A.I. Materials used as PCM in thermal energy storage in buildings: A review. Renew. Sustain. Energy Rev. 2011, 15, 1675-1695. [CrossRef]

8. Yan, Q.; Liang, C. The thermal storage performance of monobasic, binary and triatomic polyalcohols systems. Sol. Energy 2008, 82, 656-662. [CrossRef]

9. Lacroix, M. Study of the heat transfer behavior of a latent heat thermal energy storage unit with a finned tube. Int. J. Heat Mass Transf. 1993, 36, 2083-2092. [CrossRef]

10. Feldman, D.; Shapiro, M.M.; Banu, D. Organic phase change materials for thermal energy storage. Sol. Energy Mater. 1986, 13, 1-10. [CrossRef]

11. Abhat, A. Low temperature latent heat thermal energy storage: Heat storage materials. Sol. Energy 1983, 30, 313-332. [CrossRef]

12. Chellappa, R.; Russell, R.; Chandra, D. Thermodynamic modeling of the $\mathrm{C}\left(\mathrm{CH}_{2} \mathrm{OH}\right)_{4}-\left(\mathrm{NH}_{2}\right)\left(\mathrm{CH}_{3}\right) \mathrm{C}\left(\mathrm{CH} \mathrm{H}_{2} \mathrm{OH}\right)_{2}$ binary system. Calphad 2004, 28, 3-8. [CrossRef]

13. Chandra, D.; Chellappa, R.; Chien, W.M. Thermodynamic assessment of binary solid-state thermal storage materials. J. Phys. Chem. Solids 2005, 66, 235-240. [CrossRef]

14. Mishra, A.; Talekar, A.; Shi, R.; Chandra, D. Thermodynamic assessment of orientationally disordered organic molecular crystals: Ternary system pentaeryth, itol-neopentylglycol-2-amino-2methyl-1,3, propanediol (PE-NPG-AMPL). Calphad Comput. Coupling Phase Diagr. Thermochem. 2014, 46, 108-117. [CrossRef]

15. Zalba, B.; Marín, J.M.; Cabeza, L.F.; Mehling, H. Review on thermal energy storage with phase change: Materials, heat transfer analysis and applications. Appl. Therm. Eng. 2003, 23, 251-283. [CrossRef]

16. Khalifa, A.J.N.; Suffer, K.H.; Mahmoud, M.S. A storage domestic solar hot water system with a back layer of phase change material. Exp. Therm. Fluid Sci. 2013, 44, 174-181. [CrossRef] 
17. Zhao, J.; Lv, P.; Rao, Z. Experimental study on the thermal management performance of phase change material coupled with heat pipe for cylindrical power battery pack. Exp. Therm. Fluid Sci. 2017, 82, 182-188. [CrossRef]

18. Wang, C.; Li, Q.; Wang, L.; Lan, X. Phase transition of neopentyl glycol in nanopores for thermal energy storage. Thermochim. Acta 2016, 632, 10-17. [CrossRef]

19. Farid, M.M.; Khudhair, A.M.; Razack, S.A.K.; Al-Hallaj, S. A review on phase change energy storage: Materials and applications. Energy Convers. Manag. 2004, 5, 1597-1615. [CrossRef]

20. Serrano, A.; Dauvergne, J.L.; Doppiu, S.; Del Barrio, E.P. Neopentyl glycol as active supporting media in shape-stabilized PCMs. Materials 2019, 12, 3169. [CrossRef]

21. Hasnain, S.M. Review on sustainable thermal energy storage technologies, part I: Heat storage materials and techniques. Energy Convers. Manag. 1998, 39, 1127-1138. [CrossRef]

22. Jegadheeswaran, S.; Pohekar, S.D.; Kousksou, T. Exergy based performance evaluation of latent heat thermal storage system: A review. Renew. Sustain. Energy Rev. 2010, 14, 2580-2595. [CrossRef]

23. Sharma, A.; Tyagi, V.V.; Chen, C.R.; Buddhi, D. Review on thermal energy storage with phase change materials and applications. Renew. Sustain. Energy Rev. 2009, 13, 318-345. [CrossRef]

24. Zhou, D.; Zhao, C.Y.; Tian, Y. Review on thermal energy storage with phase change materials (PCMs) in building applications. Appl. Energy 2012, 92, 593-605. [CrossRef]

25. Chen, Z.; Fang, G. Preparation and heat transfer characteristics of microencapsulated phase change material slurry: A review. Renew. Sustain. Energy Rev. 2011, 15, 4624-4632. [CrossRef]

26. Delgado, M.; Lázaro, A.; Mazo, J.; Zalba, B. Review on phase change material emulsions and microencapsulated phase change material slurries: Materials, heat transfer studies and applications. Renew. Sustain. Energy Rev. 2012, 16, 253-273. [CrossRef]

27. Tyagi, V.V.; Kaushik, S.C.; Tyagi, S.K.; Akiyama, T. Development of phase change materials based microencapsulated technology for buildings: A review. Renew. Sustain. Energy Rev. 2011, 15, 1373-1391. [CrossRef]

28. Murrill, E.; Breed, L. Solid-solid phase transitions determined by differential scanning calorimetry. Part I. Tetrahedral substances. Thermochim. Acta 1970, 1, 239-246. [CrossRef]

29. Divi, S.; Chellappa, R.; Chandra, D. Heat capacity measurement of organic thermal energy storage materials. J. Chem. Thermodyn. 2006, 38, 1312-1326. [CrossRef]

30. Wang, X.; Lu, E.; Lin, W.; Liu, T.; Shi, Z.; Tang, R.; Wang, C. Heat storage performance of the binary systems neopentyl glycol/pentaerythritol and neopentyl glycol/trihydroxy methyl-aminomethane as solid-solid phase change materials. Energy Convers. Manag. 2000, 41, 129-134. [CrossRef]

31. Chandra, D.; Chien, W.M.; Gandikotta, V.; Lindle, D.W. Heat Capacities of "Plastic Crystal" Solid State Thermal Energy Storage Materials. Z. Fur Phys. Chem. 2002, 216, 1433. [CrossRef]

32. Suga, H. Calorimetric studies of some energy-related materials. Thermochim. Acta 1999, 328, 9-17. [CrossRef]

33. Ludwig, A.; Mogeritsch, J.P.; Pfeifer, T. In-situ observation of coupled peritectic growth in a binary organic model alloy. Acta Mater. 2017, 126, 329-335. [CrossRef]

34. Ludwig, A.; Mogeritsch, J. Compact seaweed growth of peritectic phase on confined, flat properitectic dendrites. J. Cryst. Growth 2016, 455, 99-104. [CrossRef]

35. Mogeritsch, J.P.; Abdi, M.; Ludwig, A. Investigation of peritectic solidification morphologies by using the binary organic model system TRIS-NPG. Materials 2020, 13, 966. [CrossRef]

36. Barrio, M.; López, D.O.; Tamarit, J.L.; Negrier, P.; Haget, Y. Degree of miscibility between non-isomorphous plastic phases: Binary system NPG (neopentyl glycol)-TRIS[tris(hydroxymethyl)aminomethane]. J. Mat. Chem. 1995, 5, 431-439. [CrossRef]

37. Lide, D.R. CRC Handbook of Chemistry and Physics, 90th ed.; CD-ROM Version 2010; CRC Press: Boca Raton, FL, USA, 2009; ISBN 9781420090840.

38. Langmuir, I. The vapor pressure of metallic tungsten. Phys. Rev. 1913, 2, 329-342. [CrossRef]

39. Price, D.M. A fit of the vapours. Thermochim. Acta 2015, 622, 44-50. [CrossRef]

40. Flynn, J.H.; Dickens, B. Steady-state parameter-jump methods and relaxation methods in thermogravimetry. Thermochim. Acta 1976, 15, 1-16. [CrossRef]

41. Price, D.M. Vapor pressure determination by thermogravimetry. Thermochim. Acta 2001, 367-368, 253-262. [CrossRef]

42. De Kruif, C.G.; Blok, J.G. The vapour pressure of benzoic acid. J. Chem. Thermodyn. 1982, 14, 201-206. [CrossRef]

43. Murata, S.; Sakiyama, M.; Seki, S. Enthalpy of sublimation of benzoic acid and dimerization in the vapor phase in the temperature range from 320 to $370 \mathrm{~K}$. J. Chem. Thermodyn. 1982, 14, 723-731. [CrossRef]

44. Santos-Moreno, S.; Doppiu, S.; Lopez, G.A.; Marinova, N.; Serrano, Á.; Silveira, E.; del Barrio, E.P. Study of the phase transitions in the binary system NPG-TRIS for thermal energy storage applications. Materials 2020, 13, 1162. [CrossRef]

45. Mogeritsch, J.P.; Ludwig, A.; Eck, S.; Grasser, M.; McKay, B.J. Thermal stability of a binary non-faceted/non-faceted peritectic organic alloy at elevated temperatures. Scr. Mater. 2009, 60, 882-885. [CrossRef]

46. Barrio, M.; López, D.O.; Tamarit, J.L.; Negrier, P.; Haget, Y. Molecular interactions and packing in molecular alloys between nonisomorphous plastic phases. J. Solid State Chem. 1996, 124, 29-38. [CrossRef]

47. Strauss, R.; Braun, S.; Dou, S.Q.; Fuess, H.; Weiss, A. Phase diagram of the orientationally order-disorder binary system 2,2-dimethyl-1,3-propanediol/2,2-dimethyl-1,3-diaminopropane, [(CH3)2C(CH2OH)2]x [(CH3)2C(CH2NH2)2]1-x. A thermodynamic, X-ray, and 1H-NMR study. Z. Fur Naturforsch. Sect. A J. Phys. Sci. 1996, 51, 871-881. [CrossRef] 
48. Eilerman, D.; Rudman, R. Polymorphism of crystalline poly(hydroxymethyl) compounds. III. The structures of crystalline and plastic tris(hydroxymethyl)aminomethane. J. Chem. Phys. 1980, 72, 5656. [CrossRef]

49. Witusiewicz, V.T.; Sturz, L.; Hecht, U.; Rex, S. Thermodynamic description and unidirectional solidification of eutectic organic alloys: II. $\left(\mathrm{CH}_{3}\right)_{2} \mathrm{C}\left(\mathrm{CH}_{2} \mathrm{OH}\right)_{2}-\left(\mathrm{NH}_{2}\right)\left(\mathrm{CH}_{3}\right) \mathrm{C}\left(\mathrm{CH}_{2} \mathrm{OH}\right)_{2}$ system. Acta Mater. 2004, 52, 5071-5081. [CrossRef]

50. Shi, R. Applications of CALPHAD (CALculation of PHAse diagram) modeling in organic orientationally disordered phase change materials for thermal energy storage. Thermochim. Acta 2020,683, 178461. [CrossRef]

51. Doshi, N.; Furman, M.; Rudman, R. The formation of the plastic crystal phase in several pentaerythritol derivatives. Acta Crystallogr. Sect. B Struct. Crystallogr. Cryst. Chem. 1973, 29, 143-144. [CrossRef]

52. Barrio, M.; Font, J.; López, D.O.; Muntasell, J.; Tamarit, J.L.; Negrier, P.; Chanh, N.B.; Haget, Y. Miscibility and molecular interactions in plastic phases: Binary system pentaglycerin/tris(hydroxymethyl)aminomethane. J. Phys. Chem. Solids 1993, 54, 171-181. [CrossRef]

53. López, D.O.; Van Braak, J.; Tamarit, J.L.L.; Oonk, H.A.J. Molecular mixed crystals of neopentane derivatives. A comparative analysis of three binary systems showing crossed isodimorphism. Calphad 1995, 19, 37-47. [CrossRef]

54. Benson, D.K.; Burrows, R.W.; Webb, J.D. Solid state phase transitions in pentaerythritol and related polyhydric alcohols. Sol. Energy Mater. 1986, 13, 133-152. [CrossRef]

55. Barrio, M.; Font, J.; López, D.; Muntasell, J.; Tamarit, J.L.; Chanh, N.B.; Haget, Y. Binary system neopentylglycol/pentaglycerin. J. Chim. Phys. 1990, 87, 1835-1851. [CrossRef]

56. Font, J.; Muntasell, J. Simultaneous measurements of enthalpies of sublimation and vapour pressures. Application to the polyols derived from neopentane. Thermochim. Acta 1994, 246, 57-64. [CrossRef] 